\title{
Hyperinsulinism associated with GLUD1 mutation: allosteric regulation and functional characterization of p.G446V glutamate dehydrogenase
}

Karolina Luczkowska ${ }^{1,2}$, Caroline Stekelenburg ${ }^{2,3}$, Frédérique Sloan-Béna ${ }^{4,5}$, Emmanuelle Ranza $^{5}$, Giacomo Gastaldi ${ }^{2,6}$, Valérie Schwitzgebel ${ }^{2,3}$ and Pierre Maechler ${ }^{1,2^{*}}$

\begin{abstract}
Background: Gain-of-function mutations in the GLUD1 gene, encoding for glutamate dehydrogenase (GDH), result in the hyperinsulinism/hyperammonemia HI/HA syndrome. HI/HA patients present with harmful hypoglycemia secondary to protein-induced $\mathrm{HI}$ and elevated plasma ammonia levels. These symptoms may be accompanied by seizures and mental retardation. GDH is a mitochondrial enzyme that catalyzes the oxidative deamination of glutamate to a-ketoglutarate, under allosteric regulations mediated by its inhibitor GTP and its activator ADP. The present study investigated the functional properties of the GDH-G446V variant (alias c.1496G > T, p.(Gly499Val) (NM_005271.4)) in patient-derived lymphoblastoid cells.

Results: The calculated energy barrier between the opened and closed state of the enzyme was $41 \%$ lower in GDH-G446V compared to wild-type GDH, pointing to altered allosteric regulation. Computational analysis indicated conformational changes of GDH-G446V in the antenna region that is crucial for allosteric regulators. Enzymatic activity measured in patient-derived lymphoblastoid cells showed impaired allosteric responses of GDH-G446V to both regulators GTP and ADP. In particular, as opposed to control lymphoblastoid cells, GDH-G446V cells were not responsive to GTP in the lower range of ADP concentrations. Assessment of the metabolic rate revealed higher mitochondrial respiration in response to GDH-dependent substrates in the GDH-G446V lymphoblastoid cells compared to control cells. This indicates a shift toward glutaminolysis for energy provision in cells carrying the GDH-G446V variant.

Conclusions: Substitution of the small amino acid glycine for the hydrophobic branched-chain valine altered the allosteric sensitivity to both inhibitory action of GTP and activation by ADP, rendering cells metabolically responsive to glutamine.
\end{abstract}

Keywords: Hyperinsulinism/hyperammonemia syndrome, GLUD1, Glutamate dehydrogenase, Allosteric regulation

\footnotetext{
* Correspondence: pierre.maechler@unige.ch

'Department of Cell Physiology and Metabolism, University of Geneva

Medical Center, 1206 Geneva, Switzerland

${ }^{2}$ Faculty Diabetes Center, University of Geneva Medical Center, 1206 Geneva,

Switzerland

Full list of author information is available at the end of the article
}

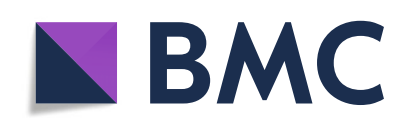

(0) The Author(s). 2020, corrected publication [2021]. Open Access This article is licensed under a Creative Commons Attribution 4.0 International License, which permits use, sharing, adaptation, distribution and reproduction in any medium or format, as long as you give appropriate credit to the original author(s) and the source, provide a link to the Creative Commons licence, and indicate if changes were made. The images or other third party material in this article are included in the article's Creative Commons licence, unless indicated otherwise in a credit line to the material. If material is not included in the article's Creative Commons licence and your intended use is not permitted by statutory regulation or exceeds the permitted use, you will need to obtain permission directly from the copyright holder. To view a copy of this licence, visit http://creativecommons.org/licenses/by/4.0/. The Creative Commons Public Domain Dedication waiver (http:// creativecommons.org/publicdomain/zero/1.0/) applies to the data made available in this article, unless otherwise stated in a credit line to the data. 


\section{Introduction}

The incidence of congenital hyperinsulinism is estimated at 1 in 50,000 (e.g., in the USA) to 1 in 2500 in certain populations (e.g., in Saudi Arabia) live births [1, 2]. Mutations in the GLUD1 gene are the second most common cause of hyperinsulinemic hypoglycemia during infancy [3, 4] with an estimate of 1 in 200,000 (ORPHA, 35878). This rare genetic disease gives rise to the hyperinsulinismhyperammonemia (HI/HA) syndrome that is caused by activating mutations in the GLUD1 gene. This gene, located on chromosome 10q23.3, is composed of 13 exons and encodes the mitochondrial enzyme glutamate dehydrogenase $(\mathrm{GDH})$. GDH catalyzes the reversible reaction $\alpha$-ketoglutarate $+\mathrm{NH}_{3}+\mathrm{NADH} \leftrightarrow$ glutamate + $\mathrm{NAD}^{+}$, the predominant flux of the reaction being tissue dependent [5]. When fueling the tricarboxylic acid cycle in the anaplerotic direction, the reaction serves as energy supplier by means of glutaminolysis. GDH is allosterically regulated, in particular by the inhibitory action of GTP and the activator ADP [6].

The clinical importance of the complex GDH allosteric regulations was originally uncovered by the discovery of a severe hypoglycemic disorder in children [7]. The phenotype of the patients is heterogeneous with neonatal and early infancy-onset of hypoglycemia, as well as elevations of plasma ammonia concentrations. GLUD1 heterozygous pathogenic variants are mainly located in the region of the GTP-binding domain or in antenna-related region. Those gain-of-function variants produce an increase in GDH activity through reduced GTP-mediated inhibition of the enzyme [8] or higher sensitivity to the allosteric activator ADP [9]. Some of these activating variants of $\mathrm{GDH}$ are associated with both $\mathrm{HI} / \mathrm{HA}$ and epilepsy [10]. Patients suffering from HI/HA syndrome display protein-induced insulin secretion, fasting hypoglycemia and increased ammonia levels independent of protein consumption. About $70 \%$ of patients are carriers of a de novo mutation; 30\% are familial cases with autosomal dominant inheritance. Our study aims at the functional and enzymatic characterization of the GDH-G446V variant (alias c.1496G>T, p.(Gly499Val) (NM_005271.4)) in lymphoblastoid cells derived from a patient identified with this pathogenic point variant.

\section{Materials and methods}

\section{Genetic analysis}

Exome sequencing at the Genome Clinic of the University Hospitals of Geneva was performed as previously described (PMID, 25691535). Targeted bioinformatics analysis of a panel of 10 genes involved in congenital hyperinsulinism (ABCC8, KCNJ11, GLUD1, GCK, HADH, HNF4A, HNF1A, SLC16A1, UCP2, CDKN1C) was done through locally developed pipelines, which select only the variants from the genes of interest, masking the rest of the data. Variants filtering and classification was performed based on the guidelines for the interpretation of sequence variants from the American College of Medical Genetics and Genomics and the Association for Molecular Pathology (PMID, 25741868).

\section{Patient-derived cell preparation}

Lymphocytes were isolated from peripheral blood of a $\mathrm{HI} / \mathrm{HA}$ patient carrying the GDH-G446V variant and of a control subject (healthy non-carrier parent) with wildtype GDH. Lymphocytes were also isolated from three additional subjects for the assessment of variability of GDH activity among various individuals. Lymphoblastoid cell lines (LCL) were established by in vitro transduction of lymphocytes B with Epstein-Barr virus [11, 12] and cultured in RPMI-1640 medium at $11.1 \mathrm{mM}$ glucose supplemented $10 \%$ (vol/vol) heat-inactivated fetal calf serum (FCS), $100 \mathrm{U} / \mathrm{ml}$ penicillin, $100 \mu \mathrm{g} / \mathrm{ml}$ streptomycin medium.

\section{GDH activity assay}

LCLs were washed with PBS and resuspended in lysis buffer containing $50 \mathrm{mM}$ Tris/ $\mathrm{HCl}, 2 \mathrm{mM}$ CDTA, and $0.2 \%$ Tween 20 ( $\mathrm{pH}$ 9.5). The cells were lysed by sonication. The GDH activity in lymphoblast homogenates was determined by the NADH autofluorescence using a Fluostar Optima (BMG Labtech) in $50 \mathrm{mM}$ Tris/HCl buffer (pH 9.5) containing $2.6 \mathrm{mM}$ EDTA and $1.4 \mathrm{mM} \mathrm{NAD}^{+}$[13]. The reaction was initiated by the addition of $5 \mathrm{mM}$ glutamate and effects of allosteric regulators GTP $(1-100 \mu \mathrm{M})$ and ADP $(300-1200 \mu \mathrm{M})$ were tested. The concentrations of the reactants and effectors were based on the estimated mitochondrial matrix volume of about $1 \mu \mathrm{L} / \mathrm{mg}$ protein, with $\mathrm{NAD}(\mathrm{H})$ in the range of $0.5-2.0 \mathrm{mM}$ [14]. Protein concentrations were determined by Bradford assay.

\section{Metabolic function}

Glycolytic and mitochondrial metabolic rates of control and mutant LCLs were assessed by the measurements of extracellular acidification rate (ECAR) and oxygen consumption rates (OCR), respectively, using the Seahorse XF 96 analyzer and the Mito stress kit (Agilent Technologies, Santa Clara, CA). After seeding in 96-well plates $\left(8 \times 10^{3}\right.$ cells/well), cells were starved for $5.5 \mathrm{~h}$ in glucose-free and bicarbonate-free $\mathrm{KRBH}(\mathrm{pH} 7.4)$ at $37^{\circ} \mathrm{C}$ without $\mathrm{CO}_{2}$. They were then metabolically stimulated with $\mathrm{GDH}$-dependent substrates $5 \mathrm{mM}$ alanine and $5 \mathrm{mM}$ glutamine for $10 \mathrm{~min}$ before blockade of mitochondrial respiration with $1 \mu \mathrm{M}$ oligomycin, induction of maximal uncoupled respiration with $1 \mu \mathrm{M}$ FCCP and finally inhibition of the electron transport chain (ETC) with $0.5 \mu \mathrm{M}$ of both rotenone and antimycin A. The OCR and ECAR measurements are reported as pmoles/ $\mathrm{min}$ and $\mathrm{mpH} / \mathrm{min}$, respectively. 


\section{Modeling and energy state of the enzyme}

Potential energy of wild type and mutant GDH was calculated using the CHARM22 algorithm [15]. The molecular models for GDH were constructed from human $\mathrm{X}$-ray structure (PDB ID: 1L1F) superimposed to bovine $\mathrm{X}$-ray crystal structures for open and closed states (PDB IDs: 3JD2 and 3JD4).

\section{Statistical analysis}

Unless otherwise indicated, data are the means \pm SD. Differences between groups were assessed by Student's $t$ test for single comparison and by one-way ANOVA for multiple comparisons (GraphPad, Prism 7.02). A $P$ value lower than 0.05 was considered as significant.

\section{Results}

\section{Clinical and genetic data}

The baby girl, carrier of the GDH-G446V variant (OMIM \# 606762), was born at term to non-consanguineous healthy parents of Eritrean origin after an uneventful pregnancy with a birth weight of $3.03 \mathrm{~kg}$ (P50), birth length 52 $\mathrm{cm}$ (P90), and head circumference of $34.5 \mathrm{~cm}$ (P50-P90). The patient has no siblings; there are no other diseases reported in the family. At the age of 4 months she was hospitalized because of hypoglycemic seizures, glucose levels were at $1.3 \mathrm{mM}$ with concomitant insulin levels of $26.68 \mu \mathrm{IU} / \mathrm{ml}$ (= $185.3 \mathrm{pM})$ compatible with congenital hyperinsulinism. Pancreatic ultrasound showed a normal-sized pancreas. Treatment with diazoxide was started at a dose of $15 \mathrm{mg} / \mathrm{kg}$ per day. The patient responded to diazoxide and the treatment was continued throughout childhood and adolescence at $50 \mathrm{mg}$ tid, since a decrease to $50 \mathrm{mg}$ bid lead to hypoglycemia of $1 \mathrm{mM}$ at the age of 10 years. Additional multiple hypoglycemic seizures with loss of consciousness were observed during young adulthood. Mild intellectual deficiency was attributed to the multiple hypoglycemic episodes. At the age of 26 years, the patient got pregnant while treated with diazoxide. At 5 weeks of gestation, she was briefly hospitalized, the blood results showed a random plasma glucose level of $3.4 \mathrm{mM}$, $\mathrm{HbA} 1 \mathrm{c}$ of $25 \mathrm{mmol} / \mathrm{mol}$ (4.4\%), and an ammonium level at $118 \mu \mathrm{M}$ (reference range 11-35). Blood pressure was $105 / 69 \mathrm{mmHg}$. A treatment change to octreotide was discussed because of the described embryotoxicity of diazoxide, classified as pregnancy category $\mathrm{C}$ according to the FDA, but the patient refused this proposal. At 11 weeks of pregnancy a trial of diazoxide discontinuation was started in association with a continuous glucose monitoring system (Dexcom G4 ${ }^{\circ}$, Dexcom, Inc., San Diego, CA, USA) in order to be alerted in case of hypoglycemia. The system recorded less than $48 \mathrm{~h}$ before the occurrence of a technical problem. Four percent of the values were below $4.4 \mathrm{mM}$, but no hypoglycemia was noted according to the definition of the international hypoglycemia study group [16]. Two days after treatment suspension, a severe hypoglycemic episode (glucose of $1.3 \mathrm{mM}$ ) occurred with loss of consciousness and treatment was reintroduced.

Exome analysis revealed a de novo heterozygous pathogenic variant in the GLUD1 gene: c.1496G>T, p.Gly499Val (NM_005271.4), referred to as GDH-G446V (see Supplemental Figure.S1). No other pathogenic or likely pathogenic variant in the gene panel analyzed was identified in the index case. Confirmation and segregation analysis of the GLUD1 variant were performed by Sanger sequencing (in the patient, her parents, and her own daughter).

Patient's daughter was born at term with intra-uterine growth restriction (IUGR) with a birth weight of $2.41 \mathrm{~kg}$ $(<2 \mathrm{SD})$, a birth length of $46 \mathrm{~cm}(<2 \mathrm{SD})$ and a head circumference of $32.5 \mathrm{~cm}(<2 \mathrm{SD})$. Cord blood glucose was $4.0 \mathrm{mM}$ with a C-peptide level of $382 \mathrm{pM}$ (reference range 370-1470); ammonium level was $110 \mu \mathrm{M}$ (reference range 0-140). Genetic analysis revealed that the daughter did not carry the GLUD1 pathogenic variant. Accordingly, the IUGR could be due to either limited metabolic fuel in the context of maternal hypoglycemia or, since diazoxide passes the placental barrier, a direct effect on fetal growth or an indirect effect via its hypotensive action potentially leading to placental hypoperfusion. The child's developmental outcome will be followed closely.

\section{Mitochondrial metabolism}

In order to study the effects of the GDH-G446V variant on cell metabolism, patient-derived LCLs were established from lymphocytes isolated from the HI/HA patient and from control subject (healthy non-carrier parent). Their respective metabolic profiles were assessed by simultaneous measurements of the extracellular acidification rate (ECAR, an indicator of glycolytic rate) and the oxygen consumption rate (OCR, an indicator of mitochondrial oxidative phosphorylation). Stimulated with GDH-dependent substrates (glutamine and alanine), both GDH-wt and GDH-G446V LCLs relied mostly on mitochondrial respiration rather than anaerobic glycolysis for energy provision (Fig. 1a, b). Inhibition of the mitochondrial ATP synthase (complex V) by oligomycin switched the source of energy provision from mitochondrial oxidative phosphorylation toward the induction of glycolysis and lactate production, as shown by the drop in the OCR and increase in ECAR, respectively (Fig. 1a, b). The change was similar in GDH-wt and GDH-G446V LCLs. However, induction of maximal respiration by a mitochondrial uncoupler prompted robust OCR in mutant cells as opposed to control LCLs. The associated further increase in ECAR was less pronounced in GDH-G446V versus GDH-wt cells. Finally, inhibition of complexes I and III confirmed that the 


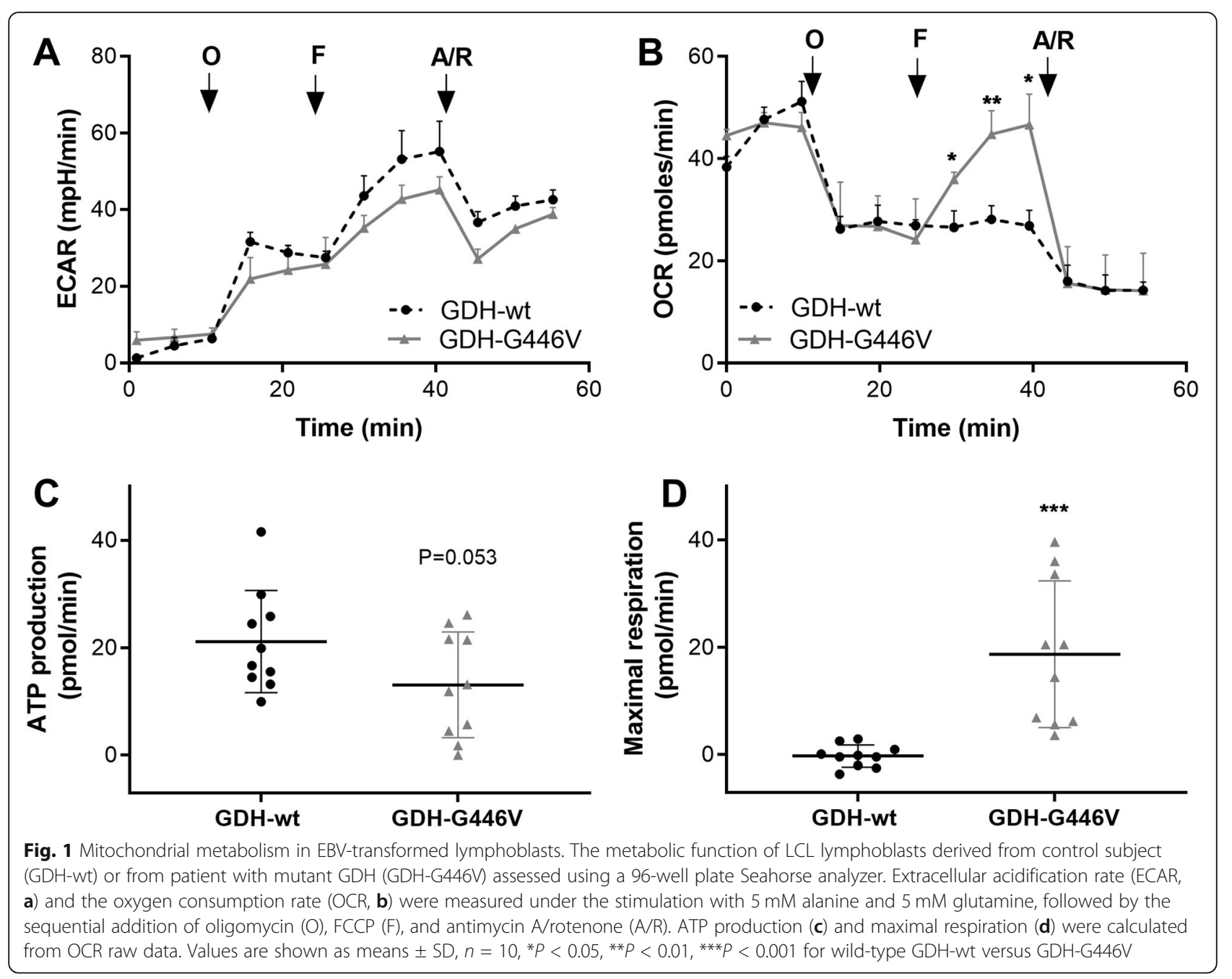

elevated respiration in mutant cells was indeed contributed by mitochondria. These data show that the overall ATP production was not affected by GDH-G446V (Fig. 1c), while the maximal mitochondrial respiration was enhanced (Fig. 1d). Therefore, the G446V mutation increased the capacity of mitochondrial metabolism in response to GDH-dependent substrates.

\section{Energetics of wtGDH and G446VGDH}

To get insight into molecular dynamics of hyperactivating mutation, the difference in potential energy was calculated between opened and closed structures for GDHG446V and GDH-wt. CHARM22 algorithm was used for calculations [15]. The energy barrier between opened and closed state in GDH-G446V was 59\% of the GDHwt (Supplemental Table). This might favor substrate/ product turnover in the mutant enzyme, which is indicative of a hyperactivity phenotype. The molecular models for GDH were derived from X-ray crystal structure for opened and closed state (PDB IDs: 3JD2 and 3JD4).

GDH is a homohexamer, structurally composed of two trimers here depicted as schematic ribbon diagram (Fig. 2, top view of the trimer, GDH-wt and GDH-G446V). GTP (location, see Fig. 2a, b) allosterically inhibits the enzyme, while ADP (location, see Fig. 2c, d) is an activator. Computational simulation of GDH-G446V model indicated conformational changes of both opened (ADP binding) and closed states (GTP binding) versus GDH-wt, pointing to altered allosteric regulation in the mutant enzyme.

\section{Enzymatic properties of GDH-G446V mutant}

The enzymatic activities of GDH-wt and GDH-G446V were measured in cell homogenates of lymphoblasts derived from control subjects and $\mathrm{HI} / \mathrm{HA}$ patient, respectively. In particular, we assessed the sensitivity to allosteric regulators, i.e., the inhibitory effect of GTP 
A

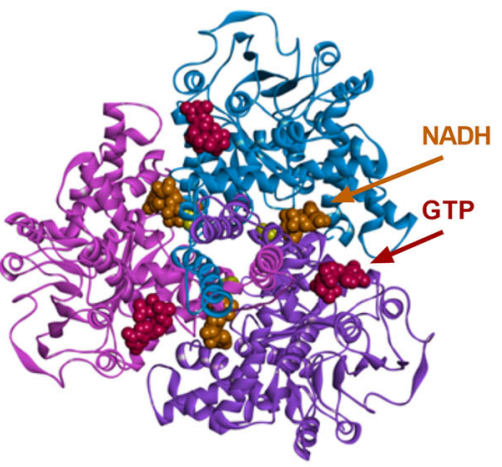

C

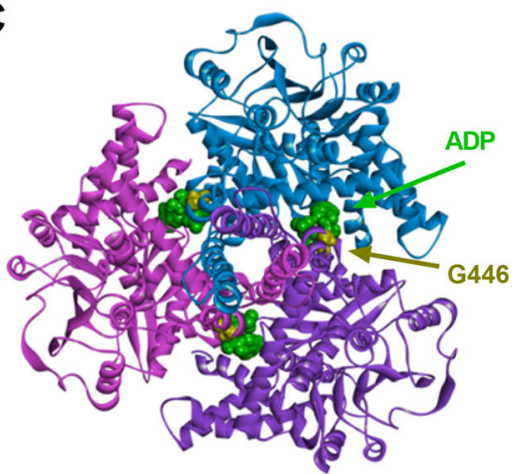

B
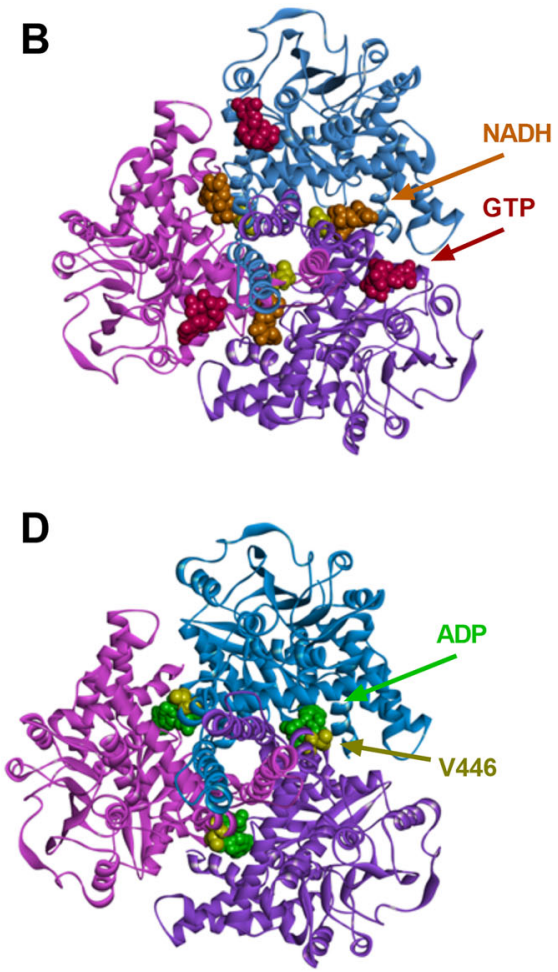

Fig. 2 GDH wild type and p.G446V molecular structures. Molecular models for closed (a, b) and opened (c, d) conformations of GDH wild type (left) and mutated form p.G446V (right) based on the structure of human GDH (PDB: 1L1F) aligned to open and closed structures of bovine GDH derived from cryo-electron microscopy [19] (PDB: 3JD2 and 3JD4). Different colors highlight each monomer of the trimer of GDH assembly displayed from the top view with location of the mutation p.G446V (yellow ball structure) and co-factors (balls structures: orange NADH and red GTP). (c, d) Single subunit of GDH (side view) with highlighted mutation on the descending helix

and the activation by ADP. Both GDH-wt and mutant GDH-G446V were responsive to a dose response of ADP (Fig. 3a). However, in the presence of $1200 \mu \mathrm{M}$ ADP, GDH-G446V exhibited higher activity compared to GDH-wt. In control GDH-wt cells, a dose response of GTP showed the strong inhibitory action of this nucleotide at $100 \mu \mathrm{M}$ (Fig. 3b). Different control subjects (males and females of different ages) exhibited similar responses to the inhibitory action of GTP (see Supplemental Figure S2). This GTP effect was effective at all of the tested concentrations of the activator ADP (Fig. 3c). In contrast, as shown in Fig. 3d, GDH-G446V cells were responsive to the inhibitory action of $100 \mu \mathrm{M}$ GTP only in the presence of the highest concentration of ADP $(1200 \mu \mathrm{M})$.

\section{Discussion}

The enzymatic characterization revealed that mutant GDH-G446V exhibits reduced sensitivity to both ADP and GTP in the higher range of their respective mitochondrial concentrations. This indicates that the mutant $\mathrm{GDH}$ would be more active in energized mitochondria (high GTP, low ADP), as well as in de-energized mitochondria (low GTP, high ADP). Such a pattern points to tissue-specific responses of mutant GDH-G446V, with a neutral inflection point at intermediate concentrations of the allosteric regulators.

The allosteric regulation of GDH is facilitated by subunit interactions contributed mainly by the antenna region, which ascends via helix structure and descends through random coil structure. Helices of the trimer wrap around each other permitting high degree of intercalation between them, thereby playing a key role in the opened/ closed conformational changes of the enzyme. Glycine to valine 446 mutation is located on the pivot of the helix, i.e., at the basis of the antenna (Fig. 4). Glycine is the amino acid with the smallest side chain and its presence introduces molecular flexibility to this region of GDH (Fig. 4a, b). On the contrary, valine is a hydrophobic branched-chain amino acid that can cause a steric interference upon clockwise motion of intercalated domains during turnover of GDH (Fig. 4c, d). Of note, the GDHG446V variant confers a different conformation of the pivot helix in the closed state (Fig. 4b, d) versus the GDH- 


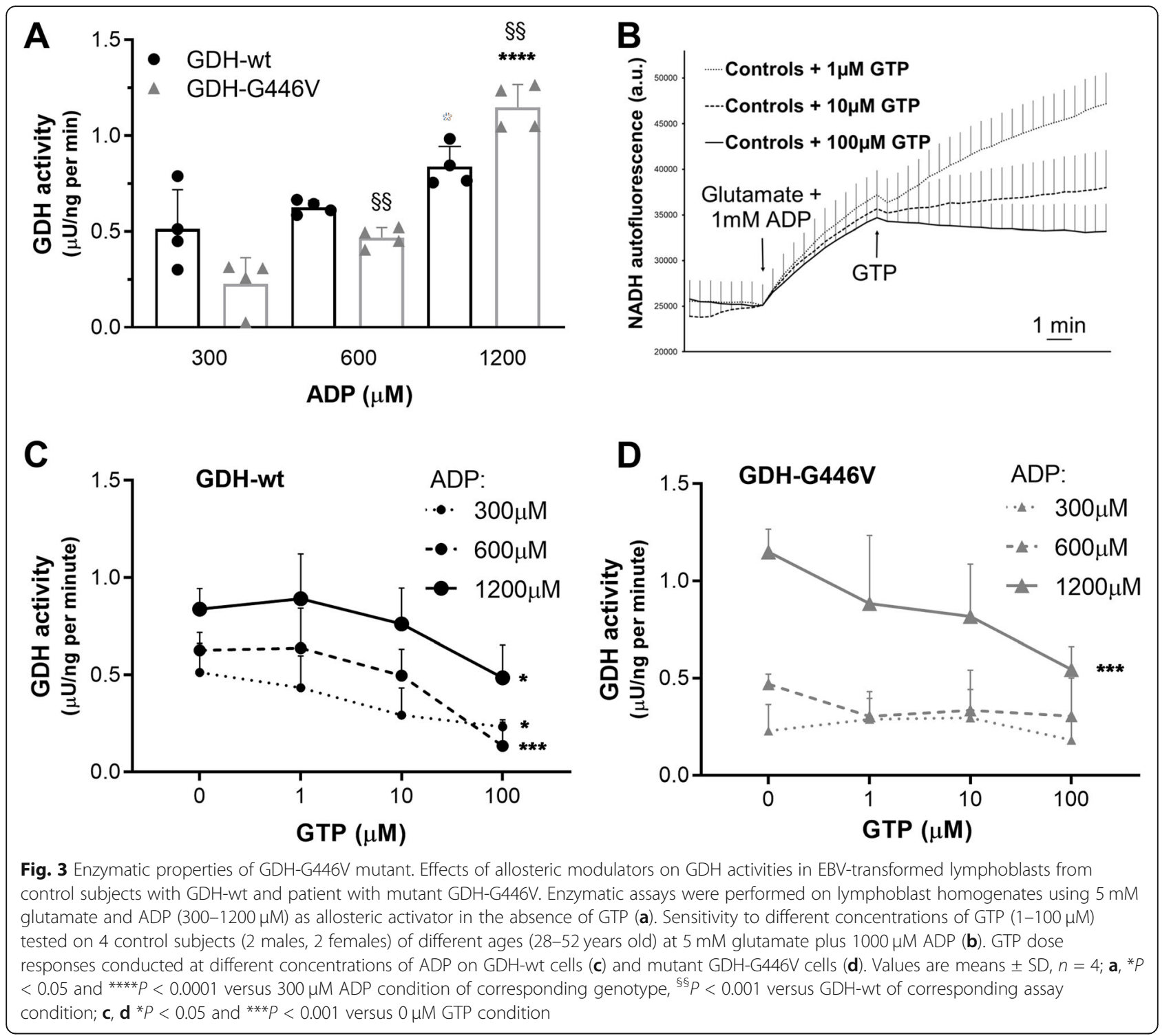

wt, probably due to compromised rotation. Most of the HI/HA patients present sporadic pathogenic variants and are therefore heterozygous. Accordingly, the respective contributions of wild type versus mutant subunits in the operating GDH hexamer are unknown. One can hypothesize that GDH-G446V patients carry heterohexamers composed of both wild type and mutant mers. Because of the expression of a strong phenotype, the mutant form appears to be dominant over wild-type subunits.

\section{Conclusions}

Authors have previously reported substitutions of glycine at position 446 for serine and aspartate [7], for arginine and valine [8], and for cysteine [17]. All of these pathogenic variants are associated with $\mathrm{HI} / \mathrm{HA}$, giving rise to impaired GTP-mediated inhibition of GDH enzymatic activity. The G446V was not yet characterized at the molecular and cellular levels. Our results show that the glycine to valine substitution at position 446 altered the GDH allosteric sensitivity to both inhibitory action of GTP and activation by ADP. In terms of cellular energetics, this was translated into increased mitochondrial metabolism in the presence of amino acids. Such an effect may render the pancreatic $ß$-cell responsive to glutamine [18], leading to inappropriate insulin secretion when the blood glucose is not stimulatory. The stimulation of insulin secretion in such a situation induces deleterious hypoglycemia. In hepatocytes, gain-of-function variant of $\mathrm{GDH}$ promotes higher ammonia production, contributing to the hyperammonemia [9]. Pathogenic 

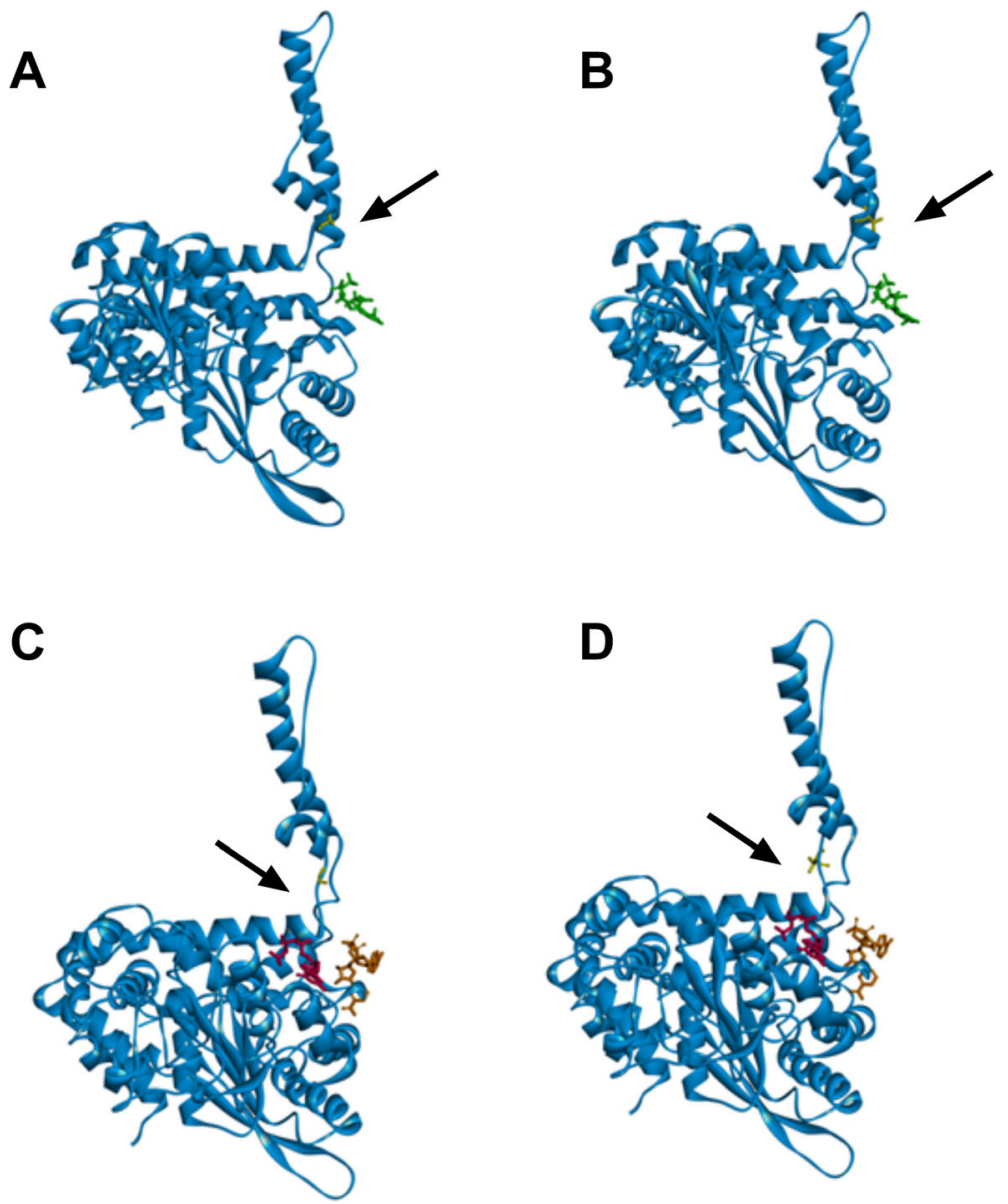

Fig. 4 Molecular structures of GDH-wt and GDH-G446V subunit. Single subunit of GDH (side view, blue) with highlighted glycine-446 (yellow) in wtGDH (arrow $\mathbf{a}, \mathbf{b}$ ) and 446-valine (yellow) in GDH-G446V (arrow $\mathbf{c}, \mathbf{d}$ ) on the descending helix in opened (a, $\mathbf{c}$ ) and closed (b, d) conformation. The pivot helix of the GDH-G446V shows a different conformation in the closed state $(\mathbf{b}$, $\mathbf{d})$ versus the GDH-wt

variants in the GLUD1 gene illustrate the complexity of allosteric regulations and the tissue specificities of the enzyme GDH, possibly contributed by the actual concentrations of the allosteric effectors, namely GTP and ADP. In situ investigations should be conducted to dig into these convoluted mechanisms.

\section{Supplementary information}

Supplementary information accompanies this paper at https://doi.org/10 1186/s40246-020-00262-8.

Additional file 1: Supplemental Table. Potential energy calculated for opened and closed state of GDH-wtand GDH-G446V. Supplemental Figure S1. GLUD1 genomic DNA sequence. Analysis shows C.1496G $>$ T variant in the DNA of the HI/HA patient. Supplemental Figure S2. Effects of the allosteric modulator GTP on GDH activity in EBV-transformed lymphoblasts from 4 control subjects; 2 males in their 6 th(M50+) and 4 th( $(\mathrm{M} 30+)$ decade of age and 2 females in their $3 r d(F 20+)$ and 5 th(F40+) decade. Enzymatic assays were performed on lymphoblast homogenates using $5 \mathrm{mM}$ glutamate and $1 \mathrm{mM}$ ADP as allosteric activator in the presence of 1-100 $\mu \mathrm{M}$ GTP.

\section{Acknowledgements}

The authors thank Prof. Michel Boulvain (University Hospitals of Geneva) for clinical support and Gaelle Chaffard (University of Geneva) for technical help.

\section{Authors' contributions}

$\mathrm{KL}$ designed and performed the experiments, analyzed data, and participated to the writing of the manuscript; CS generated the molecular structures and interpretation; VMS helped to write the manuscript; ER performed the genetic analysis and interpretation; FSB created the lymphoblastoid cell line; GG provided clinical data; PM designed and supervised the research, analyzed the data, and wrote the manuscript. All authors revised the manuscript. The authors read and approved the final manuscript.

\section{Funding}

This work was supported by the State of Geneva and the Swiss National Science Foundation (\#166625 to P.M., CR3313_140655 and CR3313_1166591 to V.M.S).

Availability of data and materials

Data will be uploaded to a public repository after manuscript acceptance (https://yareta.unige.ch//frontend/). 


\section{Ethics approval and consent to participate}

Informed consent was obtained from all the study participants or from their legal representatives and is in accordance with the declaration of Helsinki.

\section{Competing interests}

The authors declare that they have no competing interests.

\section{Author details}

${ }^{1}$ Department of Cell Physiology and Metabolism, University of Geneva Medical Center, 1206 Geneva, Switzerland. ${ }^{2}$ Faculty Diabetes Center, University of Geneva Medical Center, 1206 Geneva, Switzerland. ${ }^{3}$ Pediatric Endocrine and Diabetes Unit, Department of Pediatrics Gynecology and Obstetrics, University Hospitals of Geneva, Geneva, Switzerland. ${ }^{4}$ Department of Genetic Medicine and Development, Faculty of Medicine, University of Geneva, 1211 Geneva, Switzerland. ${ }^{5}$ Department of Genetic Medicine and Laboratory, University Hospitals of Geneva, 1211 Geneva, Switzerland. ${ }^{6}$ Division of Endocrinology, Diabetology, Hypertension and Nutrition, Geneva University Hospitals, 1211 Geneva, Switzerland.

Received: 3 December 2019 Accepted: 2 March 2020

Published online: 06 March 2020

\section{References}

1. De Leon DD, Stanley CA. Congenital hypoglycemia disorders: new aspects of etiology, diagnosis, treatment and outcomes: highlights of the proceedings of the Congenital Hypoglycemia Disorders Symposium, Philadelphia April 2016. Pediatr Diabetes. 2017;18(1):3-9.

2. Yorifuji T. Congenital hyperinsulinism: current status and future perspectives. Ann Pediatr Endocrinol Metab. 2014;19(2):57-68.

3. Palladino AA, Stanley CA. The hyperinsulinism/hyperammonemia syndrome. Rev Endocr Metab Disord. 2010;11(3):171-8.

4. Galcheva S, Demirbilek H, Al-Khawaga S, Hussain K. The genetic and molecular mechanisms of congenital hyperinsulinism. Front Endocrinol (Lausanne). 2019;10:111.

5. Karaca M, Frigerio F, Maechler P. From pancreatic islets to central nervous system, the importance of glutamate dehydrogenase for the control of energy homeostasis. Neurochem Int. 2011;59(4):510-7.

6. Smith TJ, Peterson PE, Schmidt T, Fang J, Stanley CA. Structures of bovine glutamate dehydrogenase complexes elucidate the mechanism of purine regulation. J Mol Biol. 2001;307(2):707-20.

7. Stanley CA, Lieu YK, Hsu BY, Burlina AB, Greenberg CR, Hopwood NJ, Perlman K, Rich BH, Zammarchi E, Poncz M. Hyperinsulinism and hyperammonemia in infants with regulatory mutations of the glutamate dehydrogenase gene. N Engl J Med. 1998;338(19):1352-7.

8. Stanley CA, Fang J, Kutyna K, Hsu BY, Ming JE, Glaser B, Poncz M. Molecular basis and characterization of the hyperinsulinism/hyperammonemia syndrome: predominance of mutations in exons 11 and 12 of the glutamate dehydrogenase gene HI/HA Contributing Investigators. Diabetes. 2000:49(4):667-73.

9. Grimaldi M, Karaca M, Latini L, Brioudes E, Schalch T, Maechler P. Identification of the molecular dysfunction caused by glutamate

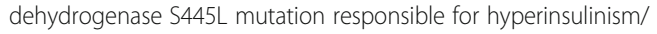
hyperammonemia. Hum Mol Genet. 2017;26(18):3453-65.

10. Kapoor RR, Flanagan SE, Fulton P, Chakrapani A, Chadefaux B, Ben-Omran T, Banerjee I, Shield JP, Ellard S, Hussain K. Hyperinsulinism-hyperammonaemia syndrome: novel mutations in the GLUD1 gene and genotype-phenotype correlations. Eur J Endocrinol. 2009;161(5):731-5.

11. Sie L, Loong S, Tan EK. Utility of lymphoblastoid cell lines. J Neurosci Res. 2009;87(9):1953-9.

12. Hussain T, Mulherkar R. Lymphoblastoid cell lines: a continuous in vitro source of cells to study carcinogen sensitivity and DNA repair. Int J Mol Cell Med. 2012;1(2):75-87.

13. Vetterli L, Carobbio S, Pournourmohammadi S, Martin-Del-Rio R, Skytt DM, Waagepetersen HS, Tamarit-Rodriguez J, Maechler P. Delineation of glutamate pathways and secretory responses in pancreatic islets with betacell specific abrogation of the glutamate dehydrogenase. Mol Biol Cell. 2012;23(19):3851-62

14. Lenartowicz E. A complex effect of arsenite on the formation of alphaketoglutarate in rat liver mitochondria. Arch Biochem Biophys. 1990;283(2): 388-96.
15. Brooks BR, Brooks CL 3rd, Mackerell AD Jr, Nilsson L, Petrella RJ, Roux B, Won Y, Archontis G, Bartels C, Boresch S, et al. CHARMM: the biomolecular simulation program. J Comput Chem. 2009;30(10):1545-614.

16. International Hypoglycaemia Study G. Glucose concentrations of less than 3. $0 \mathrm{mmol} / \mathrm{L}(54 \mathrm{mg} / \mathrm{dL})$ should be reported in clinical trials: a joint position statement of the American Diabetes Association and the European Association for the Study of Diabetes. Diabetes Care. 2017;40(1):155-7.

17. Chik KK, Chan CW, Lam CW, Ng KL. Hyperinsulinism and hyperammonaemia syndrome due to a novel missense mutation in the allosteric domain of the glutamate dehydrogenase 1 gene. J Paediatr Child Health. 2008;44(9):517-9.

18. Maechler P. Glutamate pathways of the beta-cell and the control of insulin secretion. Diabetes Res Clin Pract. 2017;131:149-53.

19. Borgnia MJ, Banerjee S, Merk A, Matthies D, Bartesaghi A, Rao P, Pierson J, Earl LA, Falconieri V, Subramaniam S, et al. Using Cryo-EM to map small ligands on dynamic metabolic enzymes: studies with glutamate dehydrogenase. Molecular pharmacology. 2016;89(6):645-51.

\section{Publisher's Note}

Springer Nature remains neutral with regard to jurisdictional claims in published maps and institutional affiliations.
Ready to submit your research? Choose BMC and benefit from:

- fast, convenient online submission

- thorough peer review by experienced researchers in your field

- rapid publication on acceptance

- support for research data, including large and complex data types

- gold Open Access which fosters wider collaboration and increased citations

- maximum visibility for your research: over $100 \mathrm{M}$ website views per year

At BMC, research is always in progress.

Learn more biomedcentral.com/submissions 